\title{
The influence of immigration on the latitude gradient of melanoma in Australia
}

\author{
Dr. D. Czarnecki* \\ Doctor's Care Network, Australia
}

\begin{abstract}
Introduction: Melanoma incidence in higher in white populations living close to the equator. Lancaster termed this the latitude gradient. The latest data on invasive melanoma in Australia suggest that there is no latitude gradient when Aged Standardized Rate (ASR) for the entire population is used to determine the incidence of melanoma. In this article the crude rate (CR) of melanoma for the susceptible population is calculated to see if the latitude gradient is present in eastern Australia. The major population centres are spread out over a distance of 2880 kilometres (1790 miles).
\end{abstract}

Materials and methods: The latest data on invasive melanoma were for 2016 and were obtained from the Australian Institute of Health and Welfare. The data on the Australian population were from the 2016 Census and were obtained from the Australian Bureaux of statistics. Country of birth of people living in Australian and country of birth of the parents of the Australian born population were used to calculate the population susceptible to melanoma.

Results: The CR of invasive melanoma, for the susceptible population, shows that the latitude gradient is present along the east coast of the continent.

Conclusion: The Australian population has greatly changed because of immigration and the number of people susceptible to melanoma is decreasing. Epidemiologists will have to take this change into account when calculating the incidence of melanoma or misleading results will be obtained.

\section{Introduction}

The incidence of melanoma in white people is higher in regions closer to the equator and this had been labelled the latitude gradient [1]. The exception is Europe and most likely explanation for this is that people with darker skin, who are less likely to develop melanoma, live closer to the equator [2]. However, within individual European countries there is a latitude gradient with the incidence of melanoma being higher in regions closer to the equator in Nordic countries, the United Kingdom, and Italy [3-5].

In Australia, the number of people diagnosed with invasive melanoma has increased every year since cases were recorded in 1982. The age standardized rates (ASR) per 100,000 people, for the entire population, do not appear to show a latitude gradient along the east coast of Australia [6]. Tasmania is the Australian region furthest from the equator but in 2016 had an ASR of 51.6, which is significantly higher than in the state of Victoria with an ASR of $41.1(\mathrm{p}<0.001)$. In Victoria, the bulk of the population lives $460 \mathrm{Km}$ (285 miles) closer to the equator. The ASR for Tasmania is only slightly lower than for the state of New South Wales (53.6), but not significantly lower. In New South Wales, most of the population lives $900 \mathrm{Km}$ (560 miles) closer to the equator than do Tasmanians.

The state of Queensland is closest to the equator and the ASR of 74.6, which was the highest in the world. However, Queensland has a large population living in the subtropical southwest and a large population living in the tropics. The incidence of melanoma has not been separately determined for these population centres that are 1,100 Km (683 miles) apart.

The Australian population has greatly changed in the last 40 years with many migrating from Asia, the Middle East, and the Pacific
Islands. These people have a low risk for melanoma [7] and including them in the population when determining the incidence of melanoma will distort the data [8]. In this article the incidence of melanoma is determined for the susceptible population in the major population centres along the east coast of Australia to see if the latitude gradient is present. The data are for 2016 when the last Census was held.

\section{Materials and methods}

Data for invasive melanoma were obtained from State Cancer registries [6]. In Australia pathologists are obliged by law to report every case of invasive melanoma to the local Cancer Registry. Data on the Australian population were obtained from the Australian Bureau of Statistics [9]. The ABS provides information on the country of birth of people living in each state but does not give the person's race. The data are for the Census Year of 2016 because this was the latest year with all information available $[6,9]$.

The country of birth for people living in each state was determined. People at low risk for melanoma were defined as those born in Asia, the Pacific Islands (not including New Zealand), the Middle East, and subSaharan Africa (not including South Africa or Zimbabwe), and their Australian born children. Also included were Australian Aborigines and Maoris who migrated from New Zealand as these indigenous people have dark skin and a low risk for melanoma.

${ }^{\star}$ Correspondence to: D Czarnecki, Doctor's Care Network, 157 Scoresby Rd, Boronia, 3155, Australia, E-mail: dbczarnecki@gmail.com

Received: December 24, 2020; Accepted: December 29, 2020; Published: December 31, 2020 


\begin{tabular}{|c|c|c|c|c|}
\hline Region & Latitude & Melanoma & $\begin{array}{c}\text { Population } \\
\text { susceptible }\end{array}$ & $\begin{array}{c}\text { CR of } \\
\text { melanoma** }\end{array}$ \\
\hline TAS & $42^{\circ} \mathrm{S}$ & 334 & 482,844 & 69.2 \\
\hline VIC & 37.8 & 2,837 & $4,484,151$ & 63.3 \\
\hline NSW & 33.8 & 4,807 & $5,559,712$ & 86.5 \\
\hline SW QLD & 27.4 & 2,841 & $3,210,039$ & 88.5 \\
\hline Tropical QLD* & $17^{\circ} \mathrm{S}$ & 650 & 775,569 & 83.8 \\
\hline
\end{tabular}

Table 1. Melanoma in Eastern Australian population Centres for 2016

* Major city - Cairns

** Crude Rate per 100,000 of the susceptible population

The vast majority of each state's population lives in the capital cities of each state: Hobart for the state of Tasmania (TAS), Melbourne for the state of Victoria (VIC), Sydney for the state of New South Wales (NSW), and Brisbane for the state of Queensland (QLD). Data for the states of TAS, VIC, and NSW were for the entire state population. The data for QLD were separately calculated for southwest QLD, which is in the temperate zone, and for tropical QLD (11). These population centres are 1,100 kilometres apart.

\section{Results}

The total population for the regions was 955,177 for tropical QLD; 3,742,780 for south west QLD; 7,480,228 for NSW; 5,926,624 for VIC; and 509,965 for TAS. The susceptible population was 775,569 for tropical QLD; 3,210,039 for south west QLD; 5,559,712 for NSW; $4,484,151$ for VIC; and 482,844 for TAS.

The crude rates (CR) of melanoma for the susceptible population in these regions are set out in the table 1 . The CR was 83.8 in tropical QLD; 88.5 for subtropical QLD; 86.5 in NSW; 63.3 in VIC; and 69.2 in TAS. The CR of melanoma in TAS was not significantly higher than in VIC. The rate for temperate QLD was not significantly different from that of tropical QLD.

\section{Discussion}

The results of the study show that there is a latitude gradient for melanoma in Australia when the population is adjusted to only include the susceptible population. The ASR in Tasmania is slightly higher than in VIC but this can be accounted for by the Europeans who migrated to each state. In the 1947 Australian Census, only $0.1 \%$ of Tasmanians and $0.1 \%$ of Victorians were born in Italy, Greece, or Malta (9). After World War 2 mass migration from Europe to Australia occurred. In the 1966 Australian Census, $0.6 \%$ of Tasmanians were born in Southern Europe compared to $6.3 \%$ of Victorians. Southern Europeans have a lower risk for melanoma than migrants from the United Kingdom or Central Europe [7].

Another possible reason for the reason for Tasmania having a higher ASR than Victoria is recent immigration from Europe. Australia admitted a yearly average of 75,000 migrants until the early 2000 s. Since 2007 the number increased to an average of 250,000 a year [7]. The European migrants would not have been exposed to the same amount of ultraviolet light during their lifetimes as the Australianborn population and so would be at lower risk for melanoma [10]. The majority of migrants settle in Victoria and New South Wales with few settling in Tasmania. These two factors are probably the reason why the CR for melanoma is lower in tropical QLD than temperate QLD. Few migrants settle in the tropics. In QLD, the 2016 Census found that $4.4 \%$ of people living in South West QLD were born in Europe compared to $2.8 \%$ in tropical QLD.

Epidemiologists determine ASRs because cancer is more common in elderly people and the number of elderly Australians is rising. However, with regard to melanoma, race is a more important variable. Throughout the world where there are large numbers of white and darkskinned people living in the same region, the incidence of melanoma is much higher in white people [11]. For example, in tropical Australia the incidence of melanoma in whites is 250 times that of Chinese and Indians living in tropical Singapore [12,13]. The incidence is uncommon in black Americans and increases with age. However, even in those aged 65 or more, the incidence in whites is 42 times that of blacks [14].

The results show that immigration has had a dramatic effect on the incidence rates of melanoma in eastern Australia. Epidemiologists will have to determine the racial composition of the population, for each age group, and then calculate the incidence of melanoma. Otherwise, misleading results will be obtained.

\section{References}

1. Lancaster HO (1956) Some geographical aspects of the mortality from melanoma in Europeans. Med J Aust 43: 1082-1087. [Crossref]

2. Elwood JM, Gallagher RP (1994) Sun exposure and the epidemiology of melanoma. In: Epidemiological Aspects of Cutaneous Malignant Melanoma, Gallagher RP, Elwood JM (Eds) Kluwer Academic Press, Boston.

3. Cicarma E, Juzeniene A, Porojnicu AC, Bruland ØS, Moan J (2010) Latitude gradient for melanoma incidence by anatomic site and gender in Norway 1966-2007. $J$ Photochem Photobiol B 101: 174-178. [Crossref]

4. Crombie IK (1979) Variation of melanoma incidence with latitude in North America and Europe. Br J Cancer 40: 774-781. [Crossref]

5. Crocetti E, Buzzoni C, Chiarugi A, Nardini P, Pimpinelli N (2012) Relationship between Latitude and Melanoma in Italy. 2012:864680. [Crossref]

6. https://www.aihw.gov.au/reports/cancer/cancer

7. https://gco.iarc.fr/

8. Czarnecki D (2014) The incidence of melanoma is increasing in the susceptible young Australian population. Acta Derm Venereol 94: 539-541.

9. https://www.abs.gov.au/

10. Holman CD, Armstrong BK (1984) Cutaneousmalignant melanoma and indicators of totalaccumulated exposure to the sun: an analysisreporting histogenetic types. $J$ Natl Cancer Inst 73: 75-82 [Crossref]

11. www.cancerqld.org.au

12. Deapen D, Bernstein L, Liu L, Kerford D, Balcius P, et al. (2007) Cancer incidence in Los Angeles County. In: Curado MP, Edwards B, Shin HR, Storm H, Ferlay J, et al. (Eds) Cancer Incidence in Five Continents. IARC Scientific, Lyon.

13. Sng J, Koh D, Wong CS, Tai BC (2009) Skin cancer trends among Asians living in Singapore from 1968-2006. J Am Acad Dermatol 61: 426-432. [Crossref]

14. Wang Y, Zhao Y, Shuangge M (2016) Racial differences in six major subtypes of melanoma: descriptive epidemiology. BMC Cancer 16: 691. [Crossref]

Copyright: (2020 Czarnecki D. This is an open-access article distributed under the terms of the Creative Commons Attribution License, which permits unrestricted use, distribution, and reproduction in any medium, provided the original author and source are credited. 